University of Montana

ScholarWorks at University of Montana

7-1985

\title{
Seasonal Changes in Feeding Success, Activity Patterns, and Weights of Nonbreeding Sanderlings (Calidris alba)
}

John L. Maron

University of Montana - Missoula, john.maron@mso.umt.edu

J. P. Myers

Academy of Natural Sciences

Follow this and additional works at: https://scholarworks.umt.edu/biosci_pubs

Part of the Biology Commons

Let us know how access to this document benefits you.

\section{Recommended Citation}

Maron, John L. and Myers, J. P., "Seasonal Changes in Feeding Success, Activity Patterns, and Weights of Nonbreeding Sanderlings (Calidris alba)" (1985). Biological Sciences Faculty Publications. 354.

https://scholarworks.umt.edu/biosci_pubs/354

This Article is brought to you for free and open access by the Biological Sciences at ScholarWorks at University of Montana. It has been accepted for inclusion in Biological Sciences Faculty Publications by an authorized administrator of ScholarWorks at University of Montana. For more information, please contact

scholarworks@mso.umt.edu. 
Seasonal Changes in Feeding Success, Activity Patterns, and Weights of Nonbreeding Sanderlings (Calidris alba)

Author(s): J. L. Maron and J. P. Myers

Source: The Auk, Vol. 102, No. 3 (Jul., 1985), pp. 580-586

Published by: University of California Press on behalf of the American Ornithologists' Union

Stable URL: http://www.jstor.org/stable/4086651

Accessed: 16/12/2013 14:37

Your use of the JSTOR archive indicates your acceptance of the Terms \& Conditions of Use, available at

http://www.jstor.org/page/info/about/policies/terms.jsp

JSTOR is a not-for-profit service that helps scholars, researchers, and students discover, use, and build upon a wide range of content in a trusted digital archive. We use information technology and tools to increase productivity and facilitate new forms of scholarship. For more information about JSTOR, please contact support@ jstor.org. 


\title{
SEASONAL CHANGES IN FEEDING SUCCESS, ACTIVITY PATTERNS, AND WEIGHTS OF NONBREEDING SANDERLINGS (CALIDRIS ALBA)
}

\author{
J. L. MARON ${ }^{1,2}$ AND J. P. MYERS ${ }^{1,3}$ \\ ${ }^{1}$ Bodega Marine Laboratory, P.O. Box 247, Bodega Bay, California 94923 USA; \\ ${ }^{2}$ Department of Biology, University of North Dakota, Grand Forks, North Dakota 58202 USA; and \\ ${ }^{3}$ The Academy of Natural Sciences, 19th and the Parkway, Philadelphia, Pennsylvania 19103 USA
}

\begin{abstract}
Seasonal changes in Sanderling (Calidris alba) feeding success, time budgets, and weights were followed throughout the nonbreeding season at Bodega Bay, California. Sanderlings spent more time roosting in fall than in winter, and in fall adults spent more time roosting than juveniles. Sanderling prey capture rates were high in fall and spring and declined through winter. Sanderling weights paralleled seasonal changes in feeding success and activity patterns: birds were heaviest in fall and spring and lightest in winter. These results reflect lowered food availability in winter and imply that birds may have difficulty balancing their energy budgets during part of the nonbreeding season. Received 6 July 1984, accepted 31 December 1984.
\end{abstract}

RESOURCE conditions faced by northern Temperate Zone shorebirds often deteriorate considerably through the nonbreeding season. Prey availability may decline due to reductions in prey density (Evans 1976, Evans et al. 1979, Goss-Custard 1980, Myers et al. 1981, Quammen 1980), changes in physical conditions of the foraging environment (Dobinson and Richards 1964, Myers et al. 1981, Pienkowski 1982), or alterations in prey behavior (Smith 1975, Reading and McGrorty 1978, Evans 1979, Pienkowski 1983).

The question is whether these alterations in prey availability have material effects on shorebird behavior. This need not be the case if the fluctuations in availability occur over a range of values where caloric intake rates are not affected-for example, in the asymptotic part of the curve relating foraging rate to prey density. Fluctuations within this range will have negligible impact on shorebirds.

If fact, many shorebirds do alter their behavior on a seasonal basis in relation to prey availability. They spend more time feeding as winter progresses (Goss-Custard 1969, 1977; Goss-Custard et al. 1977; Puttick 1979) and switch to new feeding sites or new prey (Goss-Custard 1969, Smith 1975, Evans 1976, Pienkowski 1982).

Sanderlings (Calidris alba) wintering at Bodega Bay in central coastal California experience a regular annual cycle in prey abundance (Myers et al. 1981, unpubl. data; Connors et al. 1981). Upon arrival and until midautumn, resources are abundant both on outer sandy beaches and on tidal sand flats. During winter, storms beset the beaches and drastically reduce prey numbers. Cumulative predation on sand flats also reduces prey availability (Myers et al. MS). In spring the recruitment of new prey cohorts, particularly Emerita analoga, increases prey availability on beaches once again (Connors et al. 1981). In this paper we consider whether these fluctuations in prey abundance affect local Sanderling prey capture rates, activity patterns, and weights.

\section{Study AREa AND Methods}

The study was conducted from August 1982 to April 1983 at Bodega Bay, which is along the central coast of California (Connors et al. 1981). Reference photographs are archived in VIREO (Academy of Natural Sciences).

Sanderlings arrive at Bodega Bay in July and August and depart in April and May (Myers 1980, Myers et al. 1985). Birds at Bodega Bay feed at two exposed sandy beaches during high tide and then fly to a nearby tidal sand flat to feed as the tide recedes (Connors et al. 1981).

On beaches, Sanderlings feed mostly on crustaceans, primarily the sandcrab Emerita analoga and the isopod Excirolana linguifrons (Connors et al. unpubl. data; this study). Less frequently, Sanderlings feed on small polychaetes or insects and talitrid amphipods, often from areas in and around beach wrack (Yaninek 1980, pers. obs.). On tidal sand flats, Sanderlings feed on molluscs, small crustaceans, and various polychaetes (Couch 1966, Recher 1966, Myers unpubl. data; this study).

Individual activity patterns and feeding rates. - Season- 
al changes in Sanderling feeding behavior and prey capture rates were assessed by focal animal sampling (Altmann 1974). We followed focal birds at high tide $(1.0-2.0 \mathrm{~m})$ on beaches and at low tide $(-0.3$ to +0.9 $\mathrm{m})$ on tidal flats. For behavioral observations, we walked randomly selected stretches of beach or tidal flat and, in a given group of birds, observed the banded individual next to the first banded bird sighted. We followed each focal animal for as long as it was in sight, but not longer than $10 \mathrm{~min}$, recording behavior (with a tape recorder) every $30 \mathrm{~s}$. The mean observation time per individual was $7.8 \mathrm{~min}$. After each observation period, another focal bird was chosen. In this way, different individuals feeding in a variety of social conditions were observed. We recorded prey capture continuously throughout the observation period and identified prey items whenever possible.

Prey identification was simple on outer beaches due to the marked vertical zonation of different prey (Myers 1979, Connors et al. 1981, Myers et al. 1981, pers. obs.). Prey identification on sand flats was more difficult. Prey taken could be classified as either polychaetes or "unknown." Observations were made using a 15-60 $\times$ spotting scope. We did not select roosting birds as focal animals and discontinued observations of focal individuals if they began roosting.

Many individuals were sampled several times during the season. On the beach, we sampled the same individual in more than 1 month $28 \%$ of the time and in more than 3 months $5 \%$ of the time. On tidal flats, we sampled the same individual in more than 1 month $21 \%$ of the time and in more than 3 months $3 \%$ of the time. This overlap among sample periods, a result of the random sampling procedure used to select focal animals, reduces the likelihood that differences in foraging rates among sample periods were due to differences among individuals.

We estimated tidal elevation of the focal bird every $30 \mathrm{~s}$ by recording the bird's position relative to permanent stakes of known tidal elevation. When the focal bird was not near a stake of known tidal elevation but was feeding at the tide line, tidal elevation at that location was calculated arithmetically (for details see Maron 1984). Data on birds feeding at or near the tide line were gathered within $45 \mathrm{~min}$ of the estimated low tide, to control for short-term variation in feeding success due to changes in prey behavior or in substrate penetrability caused by receding tide and drying substrate (Vader 1964, Smith 1975, Pienkowski 1983). We systematically and regularly altered our observation position to avoid site or tidalelevation biases.

To test for seasonal differences in prey capture rates on exposed beaches, we compared frequency distributions of number of prey captured per $30 \mathrm{~s}$ for September-November with those of December-March using a Kolmogorov-Smirnov two-group test. We used the same approach when analyzing capture rates on tidal flats, for which, however, we compared only distributions within the same range of tidal elevations. Prey density within our study area varies as a function of tidal elevation both on beaches and tidal flats, but Sanderlings use the beaches only over a restricted range of tidal elevations (Connors et al. 1981).

Population activity patterns. - We measured the percentage of time Sanderlings spent roosting vs. feeding using instantaneous scan sampling (Altmann 1974). To do this we recorded the behavior of birds as soon as they were spotted as we walked along the entire length of the two beaches and tidal flat. In most cases activity patterns were noted during the course of regular censuses. Scan samples were conducted at all times of day and across a wide range of tide heights and tidal elevations in all months during the study. (Tide height is used in its conventional sense. Tidal elevation, constant through time for a given site, is the absolute vertical distance between a given position on the sand flat and mean lower low water, the standard reference for tide height.) Most scan samples were taken only once per day in any given habitat; when they were taken more frequently they always were separated by at least $1 \mathrm{~h}$.

On 9 days in September and October (when juveniles and adults could be distinguished on the basis of plumage differences), we determined the percentage of juveniles and adults that were roosting at high tide.

To determine whether birds spent more daylight hours feeding in winter vs. fall, we calculated the mean number of daylight hours in fall and winter and multiplied these values by the mean percentage of daylight time birds spent feeding within these seasons. The mean percent daylight time birds spent feeding within a season was determined by calculating the percent of birds on beaches and tidal flats that were feeding at a given time and averaging these values from observations at all times of day (for analysis of activity patterns on beaches) and all tidal elevations (for analysis of activity patterns on tidal flats).

To determine how time of day and tidal height influenced the amount of time birds spent roosting, we performed a multiple regression using hour of day and tidal height as independent variables to predict percentage of time spent roosting. For the regression we transformed the time-of-day variable into hours before or after 1400 . The regression analysis was performed separately for beach and tidalflat data.

Weights. - We caught Sanderlings each month by placing mist nets around roosts on beaches at night. After capture, birds were weighed, color-banded, measured (tarsus length, wing chord, and bill length, measured to the nearest $0.1 \mathrm{~mm}$ ), sexed (by laparotomy), and released. Weights were corrected for amount of time between capture and weighing, as 


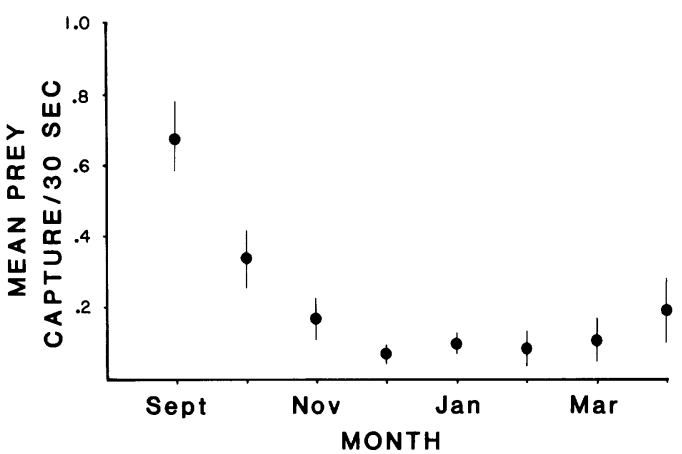

Fig. 1. Mean (and 95\% confidence intervals) prey captured per $30 \mathrm{~s}$ on beaches in various months. Sample sizes range from 148 to 464 .

weight loss increases with handling time (Lloyd et al. 1979, Schick 1983).

We analyzed weight data using an analysis of covariance, with bill size as the covariate (Gabriel's approximate method, Sokal and Rohlf 1981; see Results re correlations among weight, wing length, and body length for justification). This controlled for size-related differences in weight and yielded adjusted mean weights and $95 \%$ comparison intervals of birds caught each month. To test for potential differences between juvenile and adult weights, we pooled data from September to November and from January to March and compared weights of age groups within those periods. Comparisons were made using a multiple regression technique (Overall and Spiegel 1969), again to control for size-related weight differences.

\section{RESULTS}

Prey capture rates. - Sanderling prey capture rates on exposed sandy beaches decreased through the winter (Fig. 1). Birds captured more prey per $30 \mathrm{~s}$ in fall (September-November) than in winter (December-March; Kolmogorov-Smirnov two-group test, $D=0.124, P<$ 0.01).

Prey composition of the diet changed seasonally. More Emerita were captured in late summer and autumn than in winter, when birds increased their use of Excirolana. Emerita consumption increased once again in March and April (Fig. 2).

On the tidal flats, prey capture rates varied seasonally with tidal elevation. Within a given range of tidal elevations, Sanderlings captured more prey per $30 \mathrm{~s}$ in fall than in winter (data from tidal elevations between 0.3 and $0.9 \mathrm{~m}$ were pooled and compared between fall and winter; Kolmogorov-Smirnov two-group test,

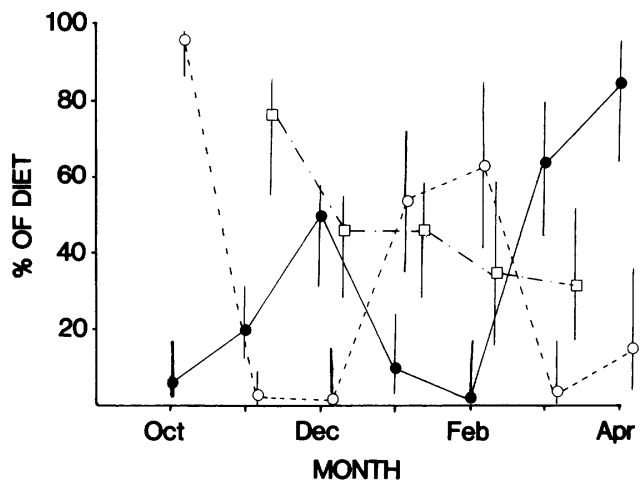

Fig. 2. The contribution (as a percentage of prey captures) that given prey comprise in Sanderling diets between October and April. Closed circles, Emerita; open circles, Excirolana; squares, other (amphipods, polychaetes, or unknown). Sample sizes range from 22 to 120 . Vertical lines are $95 \%$ confidence intervals.

$D=0.156, P<0.01)$. Within a given season, prey capture rates varied inversely with tidal elevation. Birds caught more prey per unit time while foraging at lower tidal elevations than at higher ones (Kolmogorov-Smirnov two-group test, $D=0.302, P<0.01$; Fig. 3). Polychaetes contributed most to diets of Sanderlings feeding at lower tidal elevations (Table 1). Within a given tidal height, polychaetes were taken more frequently in winter than in fall.

Population activity patterns.-Sanderlings spent more time roosting in fall (August-October) than in winter (November-March) on both the outer beaches and tidal sand flat (Figs. 4, 5). Birds fed for an average of 9.4 daylight hours (75\% of mean daylight hours) in fall and an average of 10.4 daylight hours (95\% of mean daylight hours) in winter. In fall, a greater percentage of adults than of juveniles were roosting on all 9 days sampled in September and October (ranges: $3-53 \%$ of adults vs. $0-25 \%$ of juveniles; $P<0.005$, sign test). We could not test this relationship beyond October because we could no longer reliably distinguish juveniles from adults in the field.

On beaches during fall and winter, a greater percentage of birds roosted when high tide occurred in midafternoon than when it occurred in morning $(F=15.6, \mathrm{df}=236, P<0.005$; Fig. $4)$, regardless of the height of high tide. In fact, tide height did not influence the percentage of birds roosting on beaches.

On tidal flats, in contrast, both tide height and time of day correlated with the proportion 


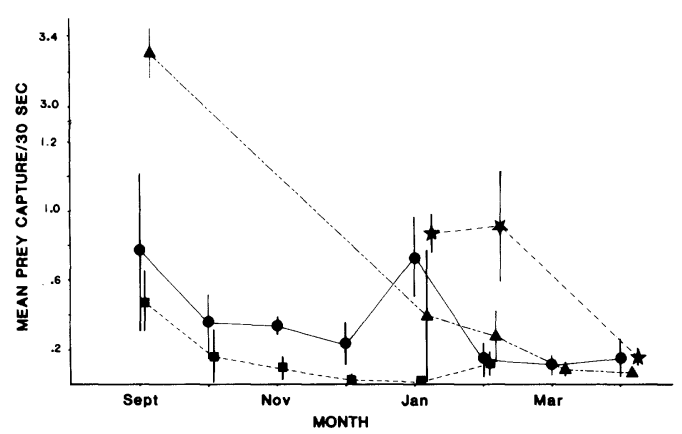

Fig. 3. Mean (and $95 \%$ confidence intervals) prey captured per $30 \mathrm{~s}$ on tidal flats at different tidal elevations in different months. Stars, tidal elevations -0.3 to $0.0 \mathrm{~m}$; triangles, tidal elevations 0.0 to $0.3 \mathrm{~m}$; circles, tidal elevations 0.3 to $0.6 \mathrm{~m}$; squares, tidal elevations 0.6 to $0.9 \mathrm{~m}$. Sample sizes range from 25 30-s intervals for tidal elevations between 0.6 and 0.9 $\mathrm{m}$ in September to 220 30-s intervals for tidal elevations between 0.3 and $0.6 \mathrm{~m}$ in January.

of birds roosting $(r=0.58, F=41.8, \mathrm{df}=162$, $P<0.005)$. Birds roosted more frequently during high vs. low tides $(P<0.05, t$-test; Fig. 5$)$ and roosted more frequently in midafternoon than in morning $(P<0.05, t$-test).

Weight.-Bill size showed a strong, positive correlation with wing length $(r=0.436, P<$ $0.01)$ and body weight $(r=0.563, P<0.01)$. The correlation of wing length to body weight was not as strong $(r=0.345, P<0.01)$. We therefore used bill size as a general indicator of body size and removed its effects in subsequent analyses with an analysis of covariance.

Weights of juvenile and adult Sanderlings did not differ significantly when compared within

TABLE 1. Contribution (as a percentage of prey captures) that polychaetes make in Sanderling diets when birds are feeding on tidal flats during different months.

\begin{tabular}{lcccc}
\hline & \multicolumn{4}{c}{ Tidal elevation (m) } \\
\cline { 2 - 5 } & $-0.3-0.0$ & $0.0-0.3$ & $0.3-0.6$ & $0.6-0.9$ \\
\hline Oct & nt & nd $^{\mathrm{b}}$ & 30 & 12 \\
Nov & nt & nd & 58 & 14 \\
Dec & nd & nd & 64 & 33 \\
Jan & 78 & 100 & 46 & 0 \\
Feb & 73 & 35 & 76 & 66 \\
Mar & nd & 55 & 0 & nd \\
Apr & 44 & 11 & nd & 50 \\
\hline
\end{tabular}

a Tide not at this elevation during this month.

b No data at this tidal elevation.

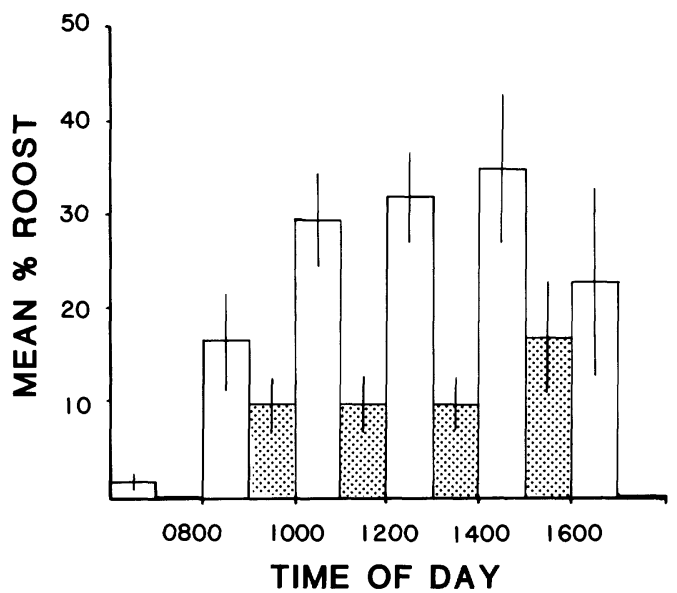

Fig. 4. Mean (and 95\% confidence intervals) percent of Sanderlings roosting on beaches (during tides between 1.1 and $1.8 \mathrm{~m}$ ) at different times of day. Open bars, fall (August-October); shaded bars, winter (November-March).

September-November or January-March (ANCOVA, $F=0.39, P>0.1$ ). To examine trends we therefore pooled adult and juvenile weights. Adjusted (using ANCOVA) mean weights of adults and juveniles were high in August-October, but dropped steadily thereafter until April (Fig. 6). The variations in weights within late summer and autumn were not significant. Late winter weights, however, did differ significantly from weights in August-November.

\section{Discussion}

The patterns we observed in Sanderling weight, time budgets, and feeding success parallel seasonal changes in prey abundance documented previously in our study area (Connors et al. 1981, Myers et al. 1981). In late summer and autumn when birds arrive at Bodega Bay, major prey items are numerous throughout the study area. As a result, Sanderling prey capture rates, weights, and proportions of time spent roosting are all high during this period. With the onset of winter, storms and accompanying rough surf erode local beaches, and prey densities plummet. Prey availability also falls on the tidal flats. Prey capture rates decline in both habitats, the proportion of time feeding vs. roosting increases, and weights decrease.

From January through March, as prey availability diminishes on the beaches, lower tidal 


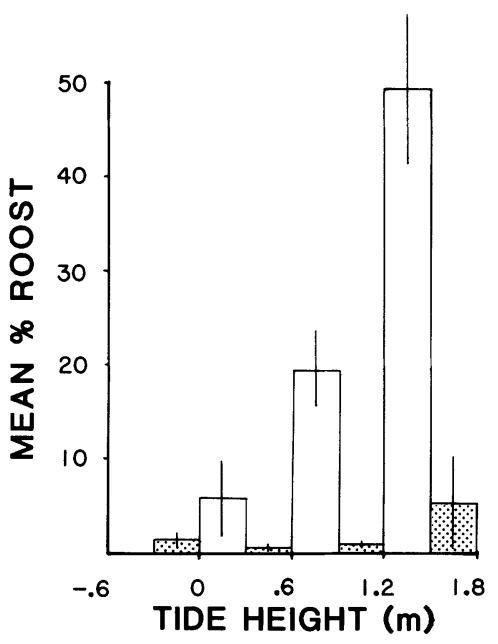

Fig. 5. Mean (and 95\% confidence intervals) percent of Sanderlings roosting on tidal flats (at all times of day) at different tidal heights. Open bars, fall (August-October); shaded bars, winter (NovemberMarch).

elevations on the tidal flats become exposed frequently during the day (Table 2; data from 1981-1982). Sanderlings readily exploit these new foraging opportunities, and in early winter, prey capture rates are in fact relatively high at these lower tidal elevations.

These changing patterns in prey capture rates, time budgets, and weights raise the question of whether the seasonal decline in resource conditions taxes an individual's ability to meet its metabolic costs of existence. Preliminary, rough estimates suggest that northern Temperate Zone wintering shorebirds may have difficulty meeting their daily existence costs during midwinter (Smith 1975, Schramm 1978, Dugan 1981, Pienkowski 1982, Maron 1984). We cannot answer this question definitively for Sanderlings without more accurate measurements of prey size, energetic expenditures, and caloric intake.

If Sanderlings do have trouble meeting their existence energy costs in midwinter, one option they have is to feed at night. Nocturnal foraging on beaches was not apparent (throughout the winter we regularly searched beaches at night for Sanderlings and never found birds feeding). Prey capture rates on beaches may be too low during midwinter to make this a sound option. We occasionally observed small numbers of Sanderlings feeding on the tidal flats at night during low tides. A

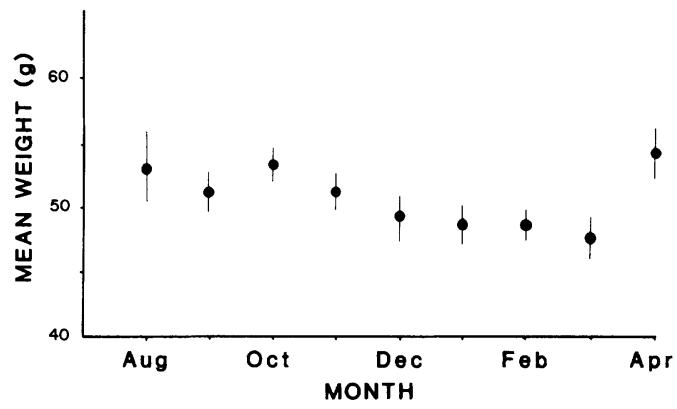

Fig. 6. Adjusted mean (and 95\% comparison intervals) weights ( $g$ ) of Sanderlings in different months. Weight adjusted for bill size. Nonoverlapping pairs are significantly different at the 0.05 level (Sokal and Rohlf 1981). Sample sizes range from 10 birds in August to 61 birds in February.

number of other shorebird species feed at night in midwinter (Goss-Custard 1969, Heppleston 1971, Baker and Baker 1973, Smith 1975, Dugan 1981, Pienkowski 1982; but see Elliot et al. 1976).

The progressive weight loss in Sanderlings at Bodega Bay resembles patterns seen in European studies in which bird weights decreased during periods of food stress (Davidson 1979, 1981; Dugan et al. 1981). Several studies, however, report that birds increase their weight in midwinter, and the authors interpret this increase as fat storage in anticipation of poor feeding conditions (Evans and Smith 1975, Dick and Pienkowski 1979, Pienkowski et al. 1979). We saw no midwinter peak in weights of Sanderlings and are unsure why our results differ from those found in other studies. Proponents of the weight-increase hypothesis might argue either that feeding conditions in California never deteriorate sufficiently to necessitate an adaptive, anticipatory increase; or that conditions are so bad that an increase is not possible (e.g. Davidson 1982). Clearly, all interpretations of patterns of wader weight

TABLE 2. Number of hours tide line remains at various tidal elevations during different months.

\begin{tabular}{lcccc}
\hline \hline & \multicolumn{4}{c}{ Tidal elevation (m) } \\
\cline { 2 - 5 } & $-0.3-0.0$ & $0.0-0.3$ & $0.3-0.6$ & $0.6-0.9$ \\
\hline Sept-Nov & $\mathrm{nt}^{\mathrm{a}}$ & 0.6 & 1.5 & 2.8 \\
Dec-Jan & 0.4 & 1.4 & 2.1 & 3.0 \\
Feb-Mar & 0.8 & 2.6 & 3.8 & 3.8 \\
\hline
\end{tabular}

a Tide not at this elevation during these months. 
changes need more critical testing before clear conclusions can be drawn (Myers et al. 1985).

Although the sharp seasonal decline in feeding success and weight paint a gloomy picture for wintering Sanderlings, it should be noted that the weather during the winter of 19821983 was more severe than usual. Rainfall at Bodega Bay was $141 \mathrm{~cm}$ in 1982-1983, compared with a mean annual rainfall of $79 \mathrm{~cm}$ for the previous 10 years. Wind speed averaged 21.2 $\mathrm{km} / \mathrm{h}$ for November-March 1982-1983, compared with $15.9 \mathrm{~km} / \mathrm{h}$ for the previous 5 winters (wind speed recorded at 0800, Bodega Marine Lab. unpubl. data).

In sum, Sanderlings wintering in central coastal California face seasonal trends in resource availability that affect their prey capture rates, activity patterns, and weights. Whether some individuals starve due to reduced prey availability is as yet unresolved. Nevertheless, it is clear that the California coast, a haven for some, is not a haven for all.

\section{ACKNOWLEDGMENTS}

This work was funded by grants to the first author from the Chapman Fund, NEEBA, the Graduate School and the Department of Biology at The University of North Dakota, and by grants to the second author from World Wildlife Fund-US and The Committee for Afternoon Projects. We are grateful to Robert $\mathrm{S}$. Lee for the use of a field vehicle. We thank Victor Chow, Jon Geller, Ilze Berzins, Greg Ruiz, Susan Haig, Mark Colwell, Diana Lieberman, Richard Crawford, and two anonymous reviewers for comments on the manuscript. We offer special thanks to Lew Oring, who offered guidance and support throughout. Warm thanks to C. Hohenberger and T. Schick, who were of invaluable help in the field, and to Paul Siri and the staff at the Bodega Marine Laboratory, who greatly facilitated our work. This paper is a contribution on the part of JLM from the Center for Ecological Education and Research at Bodega Bay, California.

\section{Literature Cited}

AltmanN, J. 1974. Observational study of behavior: sampling methods. Behaviour 49: 227-265.

BAKER, M. C., \& A. M. BAKER. 1973. Niche relationships among six species of shorebirds on thei: wintering and breeding ranges. Ecol. Monogr. 43: 193-212.

$\rightarrow$ Connors, P. G., J. P. MYERS, C. S. W. CONNORS, \& F. A. PitelKa. 1981. Interhabitat movements by Sanderlings in relation to foraging profitability and the tidal cycle. Auk 98: 49-64.
Couch, A. B. 1966. Feeding ecology of four species of sandpipers in western Washington. Unpublished M.A. thesis, Seattle, Univ. Washington.

Davidson, N. C. 1979. Changes in the body composition of shorebirds during winter. Wader Study Group Bull. 26: 29-30.

- 1981. Survival of shorebirds (Charadrii) during severe weather: the role of nutritional reserves. Pp. 231-249 in Feeding and survival strategies of estuarine organisms (N. V. Jones and W. J. Wolff, Eds.). New York, Plenum Press.

- 1982. Changes in the body-condition of Redshanks during mild winters: an inability to regulate reserves? Ringing and Migration 4: 5162.

Dick, W. J. A., \& M. W. Pienkowski. 1979. Autumn and early winter weights of waders in northwest Africa. Ornis Scandinavica 10: 117-123.

Dobinson, H. M., \& A. J. Richards. 1964. The effects of the severe winter of 1962-63 on birds in Britain. Brit. Birds 57: 734-737.

DUGAN, P. J. 1981. The importance of nocturnal foraging in shorebirds: a consequence of increased invertebrate prey activity. Pp. 251-260 in Feeding and survival strategies of estuarine organisms (N. V. Jones and W. J. Wolff, Eds.). New York, Plenum Press.

$-\rightarrow-$, P. R. Evans, L. R. GoOdYear, \& N. C. DAVIDSON. 1981. Winter fat reserves in shorebirds: disturbance of regulated levels by severe weather conditions. Ibis 123: 359-363.

Elliot, C. C. H., M. WaltneR, L. G. Underhill, J. S. PRINGle, \& W. J. A. DiCK. 1976. The migration system of the Curlew Sandpiper Calidris ferruginea in Africa. Ostrich 47: 191-213.

Evans, P. R. 1976. Energy balance and optimal foraging strategies in shorebirds: some implications for their distributions in the non-breeding season. Ardea 64: 117-139.

- 1979. Adaptations shown by foraging shorebirds to cyclical variations in the activity and availability of their intertidal prey. Pp. 357366 in Cyclic phenomena in marine plants and animals (E. Naylor and R. G. Hartnoll, Eds.). New York, Pergamon Press.

$-\rightarrow-$, D. M. Gerdson, P. J. KNIGHTS, \& M. W. PIENKOWSKI. 1979. Short-term effects of reclamation of part of Seal Sands, Teesmouth, on wintering waders and Shelduck. Oecologia 41: 183-206.

- \& P. G. SMITH. 1975. Studies of shorebirds at Lindisfarne, Northumberland. II. Fat and pectoral muscles as indicators of body condition in the Bar-tailed Godwit. Wildfowl 26: 37-46.

Goss-CustaRD, J. D. 1969. The winter feeding ecology of the Redshank Tringa totanus. Ibis 111: 338355.

-1977. Density-related behaviour and the possible effects of a loss of feeding grounds on wading birds (Charadrii). J. Appl. Ecol. 14: 721739. 
1980. Competition for food and interference among waders. Ardea 68: 31-52.

, R. A. JenYon, R. E. JONES, P. E. Newbery, \& R. Le B. Williams. 1977. The ecology of the wash. II. Seasonal variation in the feeding conditions of wading birds (Charadrii). J. Appl. Ecol. 14: 701-719.

Heppleston, P. B. 1971. The feeding ecology of Oystercatchers (Haematopus ostralegus L.) in winter in northern Scotland. J. Anim. Ecol. 40: 651672.

Lloyd, C. S., M. W. Pienkowski, \& C. D. T. Minton. 1979. Weight loss of Dunlins Calidris alpina while being kept after capture. Wader Study Group Bull. 26: 14.

MARON, J. L. 1984. Behavioral ecology of Sanderlings Calidris alba during the non-breeding season. Unpublished M.S. thesis, Grand Forks, Univ. North Dakota.

MYERS, J. P. 1979. Ecological control of spacing behavior in nonbreeding shorebirds. Unpublished Ph.D. dissertation, Berkeley, Univ. California.

- 1980. Sanderlings Calidris alba at Bodega Bay: facts, inferences, and shameless speculations. Wader Study Group Bull. 30: 26-32. , P. G. Connors, \& F. A. Pitelka. 1981. Optimal territory size and the Sanderling: compromises in a variable environment. Pp. 135-158 in Mechanisms in foraging behavior (A. C. Kamil and T. D. Sargent, Eds.). New York, Garland Press.

- J. L. MARON, \& M. SAllaberRY. 1985. Going to extremes: why do Sanderlings migrate to the Neotropics? Ornithol. Monogr. No. 36 in press.

Overall, J. W., \& D. K. SPIEgel. 1969. Concernin least squares analysis of experimental data. Psychol. Bull. 72: 311-322.

PIENKOWSKI, M. W. 1982. Aspects of the ecology and behaviour of Ringed and Grey plovers Charadrius hiaticula and Pluvialis squatarola, in the nonbreeding season. J. Zool., London 197: 511-549. $\rightarrow$ 1983. Surface activity of some intertidal invertebrates in relation to temperature and the foraging behaviour of their shorebird predators. Marine Ecol. Progr. Ser. 11: 141-150.

$\longrightarrow \rightarrow-$ C. S. Lloyd, \& C. D. T. Minton. 1979. Seasonal and migrational weight changes in Dunlins. Bird Study 26: 134-148.

PUTTICK, G. M. 1979. Foraging behavior and activity budgets of Curlew Sandpipers. Ardea 67: 111122.

QUAMMEN, M. L. 1980. The impact of predation by shorebirds, benthic feeding fish and a crab on shallow living invertebrates in intertidal mudflats of two southern California lagoons. Unpublished Ph.D. dissertation, Irvine, Univ. California.

READING, C. J., \& S. MCGRORTY. 1978. Seasonal variations in the burying depth of Macoma balthica and its accessibility to wading birds. Estuarine Coastal Marine Sci. 5: 135-144.

RECHER, H. F. 1966. Some aspects of the ecology of migrating shorebirds. Ecology 47: 393-407.

SCHICK, T. C. 1983. Weight loss in Sanderling Calidris alba after capture. Wader Study Group Bull. 38: 33-34.

SCHRAMM, M. 1978. The feeding ecology of Grey Plover on the Swartkops estuary. Unpublished honors thesis, Port Elizabeth, South Africa, Univ. Port Elizabeth.

SMITH, P. C. 1975. A study of the winter feeding ecology and behaviour of the Bar-tailed Godwit (Limosa lapponica). Unpublished Ph.D. dissertation, Durham, England, Univ. Durham.

SOKAL, R. R., \& F. J. RoHLF. 1981. Biometry. San Francisco, W. H. Freeman and Co.

$\rightarrow$ VADER, W. J. M. 1964. A preliminary investigation into the reactions of the infauna of the tidal flats to tidal fluctuations in water level. Neth. J. Sea Res. 2: 189-222.

YANINEK, J. S. 1980. Beach wrack: phenology of an important resource and utilization by macroinvertebrates of sandy beaches. Unpublished M.A. thesis, Berkeley, Univ. California. 